\title{
ESTUDO E DIMENSIONAMENTO DE UM SISTEMA DE REFRIGERAÇÃO PORTÁTIL
}

\section{ARTIGO ORIGINAL}

SANTOS, Aléxia Botelho dos ${ }^{1}$, MENDES, Ana Paula², SANTOS, Joycielle Naira dos $^{3}$, PEREIRA, Kamyla Sthephne Oliveira ${ }^{4}$, SANTOS, Larissa Maria Silva ${ }^{5}$, PEREIRA, Raiane Roberta Bueno ${ }^{6}$, SANTOS, Alexsander Saves dos ${ }^{7}$

SANTOS, Aléxia Botelho dos. Et al. Estudo e dimensionamento de um sistema de refrigeração portátil. Revista Científica Multidisciplinar Núcleo do Conhecimento. Ano. 06, Ed. 09, Vol. 01, pp. 93-113. Setembro 2021. ISSN: 2448-0959, Link de acesso:

https://www.nucleodoconhecimento.com.br/engenhariaquimica/refrigeracao-portatil,

DOI:

10.32749/nucleodoconhecimento.com.br/engenharia-quimica/refrigeracao-portatil

\section{RESUMO}

A refrigeração é uma Operação Unitária responsável pela diminuição, de forma artificial, da temperatura de um sólido ou fluído até o ponto de congelamento. O presente trabalho teve como objetivo desenvolver um refrigerador por compressão a vapor tipo portátil, leve e de baixo custo, para o resfriamento de bebidas armazenadas em latas e garrafas. A metodologia adotada foi uma pesquisa experimental, em que é apresentado todo o desenvolvimento do equipamento desde a seleção dos materiais, dimensionamento, montagem, testes de funcionamento $\mathrm{e}$ avaliação de desempenho em termos da capacidade de refrigeração. $O$ projeto comprovou sua eficiência, uma vez que apresentou uma queda de temperatura de

\footnotetext{
${ }^{1}$ Acadêmico em Engenharia Química.

${ }^{2}$ Acadêmico em Engenharia Química.

${ }^{3}$ Acadêmico em Engenharia Química.

${ }^{4}$ Acadêmico em Engenharia Química.

${ }^{5}$ Acadêmico em Engenharia Química.

${ }^{6}$ Acadêmico em Engenharia Química.

${ }^{7}$ Orientador.
}

RC: 96275

Disponível em: https://www.nucleodoconhecimento.com.br/engenhariaquimica/refrigeracao-portatil 
$27,1{ }^{\circ} \mathrm{C}$ em 150 minutos, sendo que o fluído em temperatura ambiente de $26{ }^{\circ} \mathrm{C}$, atingiu ao término do processo a temperatura de $-1,1{ }^{\circ} \mathrm{C}$, em um tempo relativamente baixo. Ademais, o trabalho promoveu dados adeptos com a literatura, gerando assim, resultados satisfatórios.

Palavras-chave: Refrigeração, Compressor, Evaporador, Temperatura.

\section{INTRODUÇÃO}

A refrigeração é uma Operação Unitária responsável pela diminuição, de forma artificial, da temperatura de um sólido ou fluído até o ponto de congelamento. Para Borgnakke e Sonntag (2002) a refrigeração pode ser definida como o processo que transfere calor de forma contínua de um ambiente refrigerado para um ambiente com temperatura mais baixa que o meio. É muito utilizada para diversos fins, como armazenamento e conservação de alimentos, climatizar ambientes, entre outros.

Nunes (2015) relata que na segunda metade do século XVIII, William Cullen (1794 1878) em 1755, diminuiu a pressão do éter para facilitar a evaporação e assim acelerar o processo de retirada de calor de uma quantidade pequena de água, notando que a temperatura baixou suficientemente para congelar a água e produzir gelo artificial. Anos depois, em 1834 Jacob Perkins (1766 - 1849) patenteou o primeiro equipamento com ciclo de refrigeração por compressão a vapor, porém, somente após 20 anos, o primeiro refrigerador foi construído. Os modelos atuais de refrigerador surgiram na segunda década do século XX e, desde então a refrigeração é imprescindível a todos.

O elemento pode constituir-se em três diferentes estados físicos, sendo estes, o estado líquido, gasoso e sólido. Entretanto, de acordo com a pressão e a temperatura, um específico tipo de elemento tem a possibilidade de se apresentar em qualquer outro estado físico. Em um sistema de refrigeração estão presentes duas transformações envolvendo a mudança de estado físico: a condensação e a vaporização. A vaporização é a passagem do estado líquido para o gasoso e ocorre 
dentro do evaporador e a condensação é a passagem do estado gasoso para o líquido e ocorre dentro do condensador (EVANGELISTA, 2010).

Por meio de uma configuração global ideal de trabalho, pode-se obter uma economia de energia em ciclos de compressão de vapor para cada equipamento do sistema e, em sequência, para todo o sistema (NUNES, 2015).

Segundo Ferraz (2008) refrigeradores são responsáveis pelo resfriamento de bebidas e alimentos, logo, existem inúmeros modelos no mercado com diferentes utilidades e temperaturas, podendo ser classificados nas categorias doméstica, comercial e industrial.

Os sistemas de refrigeração podem ser de compressão de vapor, absorção, refrigeração a ar e por efeitos termoelétricos. O sistema mais utilizado é o de compressão a vapor, enquanto os demais, apenas em condições específicas (NUNES, 2015).

Marques (2010) relata que o desempenho do ciclo de refrigeração por compressão a vapor depende, em particular, do fluído refrigerante, portanto, é importante a análise do coeficiente de desempenho do ciclo, através do Coeficiente de Performance (COP), onde é possível determinar qual fluído é mais viável para ser utilizado.

Determinados estudos apontam que para o melhoramento do desempenho dos sistemas de refrigeração é aplicado um o controle eletrônico nos equipamentos, como o comando eletrônico na velocidade do compressor e na abertura de válvula de expansão (NUNES, 2015). Assim, para que haja progresso no projeto e em seu controle contínuo, os avanços tecnológicos são essenciais para o melhor desempenho e confiabilidade dos sistemas de refrigeração (MCKINLEY; ALLEYNE, 2008).

Martínez (2009), termodinamicamente o ciclo ideal de refrigeração por compressão de vapor é composto por quatro processos, sendo um processo de compressão adiabática e reversível (compressor), desde o estado de vapor saturado até vapor

RC: 96275

Disponível em: https://www.nucleodoconhecimento.com.br/engenhariaquimica/refrigeracao-portatil 
superaquecido; um processo de rejeição de calor à pressão constante (condensador), reduzindo inicialmente a temperatura do refrigerante e condensandoo até um estado de líquido saturado; um processo de expansão irreversível, a entalpia constante (num dispositivo de expansão com redução de pressão) até atingir a pressão de evaporação; e finalmente, um processo de ganho de calor a pressão constante, resultando na evaporação do refrigerante até o estado de vapor saturado.

O fenômeno da refrigeração é resultante de transformações físicas sofridas por um fluido refrigerante durante seu percurso em um sistema fechado. Dentro de um sistema de refrigeração por compressão de vapor é composto basicamente por um compressor, condensador, um mecanismo de expansão (tubo capilar) e um evaporador (OLIVEIRA; REBELATTO; YAMASHITA, 2016).

Fluídos refrigerantes, são as substâncias empregadas como transmissores térmicos na realização dos ciclos de refrigeração. Por terem propriedades termodinâmicas, esses compostos são capazes de absorver calor, esfriando o ambiente de maneira controlada. A qualidade do fluído refrigerante é um fator fundamental para funcionamento e rendimento de sistemas de refrigeração (MORAIS, 2012).

Além de propriedades termodinâmicas, esses fluidos não devem ser tóxicos ou trazerem impactos ao meio ambiente. Rowland e Molina (1975) demostraram que o fluído refrigerante extensivamente utilizado nos sistemas de refrigeração, o CFC-12 (da família dos clorofluorcarbonos), possuía alto índice de destruição da camada de ozônio, o que fez com que fosse interrompido na década de 90, embora seus efeitos ainda sejam sentidos (SELLENT, 2011). O fluído mais usufruído em equipamentos de refrigeração no Brasil é o HFC-134A, pois independente da sua contribuição na degradação dentro da camada de ozônio ser quase inexistente, o efeito do aquecimento global continua considerável (OLIVEIRA; REBELATTO; YAMASHITA, 2016).

RC: 96275

Disponível em: https://www.nucleodoconhecimento.com.br/engenhariaquimica/refrigeracao-portatil 
Nas palavras de Carmeis (2002) e Salvador (1999), o compressor é um componente mecânico mais complexo, movido por um motor elétrico, cuja função é puxar o refrigerante vaporizado do evaporador e o comprimir em um volume pequeno a uma alta temperatura, assim, fornece um diferencial de pressão de forma que o fluido refrigerante possa evaporar a uma temperatura inferior à temperatura de condensação e assim retirar calor de uma fonte fria e rejeitar esse calor para uma fonte quente.

Condensadores são os elementos do sistema de refrigeração que têm a função de transformar o gás quente, que é descarregado do compressor a alta pressão, em líquido. Para isso, rejeita o calor contido no fluido refrigerante para alguma fonte de resfriamento (FERRAZ, 2008).

O dispositivo de expansão tem a função de reduzir a pressão do refrigerante desde a pressão de condensação até a pressão de vaporização. Ao mesmo tempo, este dispositivo deve regular a vazão de refrigerante que chega ao evaporador, de modo a satisfazer a carga térmica aplicada ao mesmo (SEELENT, 2011).

O evaporador é a parte do sistema de refrigeração onde o fluído refrigerante passa uma modificação de estado, deixando a fase líquida e passando para a fase gasosa. Após passar pela válvula de expansão, o fluido refrigerante é admitido no evaporador da forma líquida. Como a pressão do evaporador é baixa, o fluido refrigerante se evapora com uma temperatura baixa (JÚNIOR, 2003).

Partindo destes conceitos, o objetivo foi desenvolver um refrigerador por compressão à vapor tipo portátil, leve e de baixo custo, para o resfriamento de bebidas armazenadas em latas e garrafas, de forma agradável para o consumo humano.

\section{MATERIAIS E MÉTODOS}

O presente projeto foi realizado no período de julho a agosto de 2020 na Universidade Brasil, localizada na Estrada Projetada F-1 s/n Fazenda Santa Rita, no

RC: 96275

Disponível em: https://www.nucleodoconhecimento.com.br/engenhariaquimica/refrigeracao-portatil 
Município de Fernandópolis-SP. A pesquisa desenvolvida foi experimental e seguiu as etapas elencadas na Figura 1:

Figura 1 - Etapas de desenvolvimento do projeto

Escolha do modelo
Seleção dos

materiais
Montagem

do protótipo
Testes de

funcionamento
Avaliação de desempenho

Fonte: Os autores, 2020.As aquisições dos materiais para o desenvolvimento do projeto de refrigeração foram de recursos próprios, estabelecidos e providenciados nas proporções adequadas para o funcionamento do protótipo (Tabela 1).

Tabela 1 - Custos dos materiais utilizados e aplicações externas

\begin{tabular}{|c|c|c|c|}
\hline Material & Quantidade & $\begin{array}{l}\text { Valor Unitário } \\
(\mathrm{R} \$)\end{array}$ & $\begin{array}{l}\text { Valor Total } \\
(\mathrm{R} \$)\end{array}$ \\
\hline Abraçadeira $3,1 \mathrm{~cm} \times 1,8 \mathrm{~cm}$ & 9 & 2,00 & 18,00 \\
\hline Abraçadeira 4,2 cm x 1,8 cm & 8 & 2,75 & 22,00 \\
\hline Abraçadeira $8 \mathrm{~cm} \mathrm{x} \mathrm{1,8} \mathrm{cm}$ & 15 & 3,50 & 52,50 \\
\hline Adesivo + Arte & 1 & 25,00 & 25,00 \\
\hline Arruelas & 8 & 0,20 & 1,60 \\
\hline Caixa térmica 50 litros & 1 & 100,00 & 100,00 \\
\hline Chapa metálica $21,7 \mathrm{~cm} \mathrm{X} \mathrm{16,2} \mathrm{cm}$ & 1 & 8,00 & 8,00 \\
\hline Chapa metálica $16,1 \mathrm{~cm} \times 8,1 \mathrm{~cm}$ & 1 & 7,00 & 7,00 \\
\hline Chapa metálica $16,1 \mathrm{~cm} \times 7,1 \mathrm{~cm}$ & 1 & 7,00 & 7,00 \\
\hline $\begin{array}{l}\text { Cilindro de gás refrigerante } \\
\text { R-409A } 750 \mathrm{~g}\end{array}$ & 1 & 102,00 & 102,00 \\
\hline Controlador digital MT-512E & 1 & 160,00 & 160,00 \\
\hline Cooler & 1 & 58,90 & 58,90 \\
\hline Dimmer rotativo $1000 \mathrm{~W}$ & 1 & 18,00 & 18,00 \\
\hline Filtro secador & 1 & 9,90 & 9,90 \\
\hline
\end{tabular}

RC: 96275

Disponível em: https://www.nucleodoconhecimento.com.br/engenhariaquimica/refrigeracao-portatil 


\begin{tabular}{|l|l|l|l|}
\hline Motor de bebedouro 1/8 & 1 & 100,00 & 100,00 \\
\hline Parafuso 1" x 3/8" & 8 & 0,71 & 5,68 \\
\hline Parafuso brocante 1,3 cm & 120 & 0,12 & 14,40 \\
\hline Porcas & 8 & 0,25 & 2,00 \\
\hline Silicone PU-30 420g & 1 & 13,80 & 13,80 \\
\hline Tinta spray colorgin 350 ml & 1 & 20,00 & 20,00 \\
\hline Tubo capilar 0,50" & 3 metros & 6,67 & 20,00 \\
\hline Tubo de cobre 5/16 & 11 metros & 9,27 & 102,00 \\
\hline Tubo de cobre 3/8 & 4 metros & 11,25 & 45,00 \\
\hline Válvula schrader & 2 & 5,00 & 10,00 \\
\hline Aplicações externas (gás refrigerante no & 1 & 300,00 & 300,00 \\
\hline sistema) & & & \\
\hline & & TOTAL & $\mathbf{R} \mathbf{1 . 2 2 2 , 7 8}$ \\
\hline
\end{tabular}

Fonte: os autores, 2020.

Para que o protótipo funcionasse, seguiu-se as etapas de funcionamento do sistema de Compressão Mecânica de Vapor (CMV), de acordo com explanações de Ferraz (2008), onde o fluido refrigerante adentra no evaporador à baixa pressão, na forma de líquido mais vapor, e retira energia do meio interno enquanto passa para o estado de vapor. Após, o vapor entra no compressor onde é comprimido e bombeado, tornando-se vapor superaquecido, onde desloca-se para o condensador, que tem a função de liberar a energia retirada do ambiente. Após liberar energia, o fluido passa do estado de vapor superaquecido para líquido (condensação), entrando no dispositivo de expansão, após, a pressão é reduzida, volta ao evaporador e o ciclo inicia novamente. A Figura 2 ilustra esse sistema.

RC: 96275

Disponível em: https://www.nucleodoconhecimento.com.br/engenhariaquimica/refrigeracao-portatil 
Figura 2 - Representação de um sistema de refrigeração.

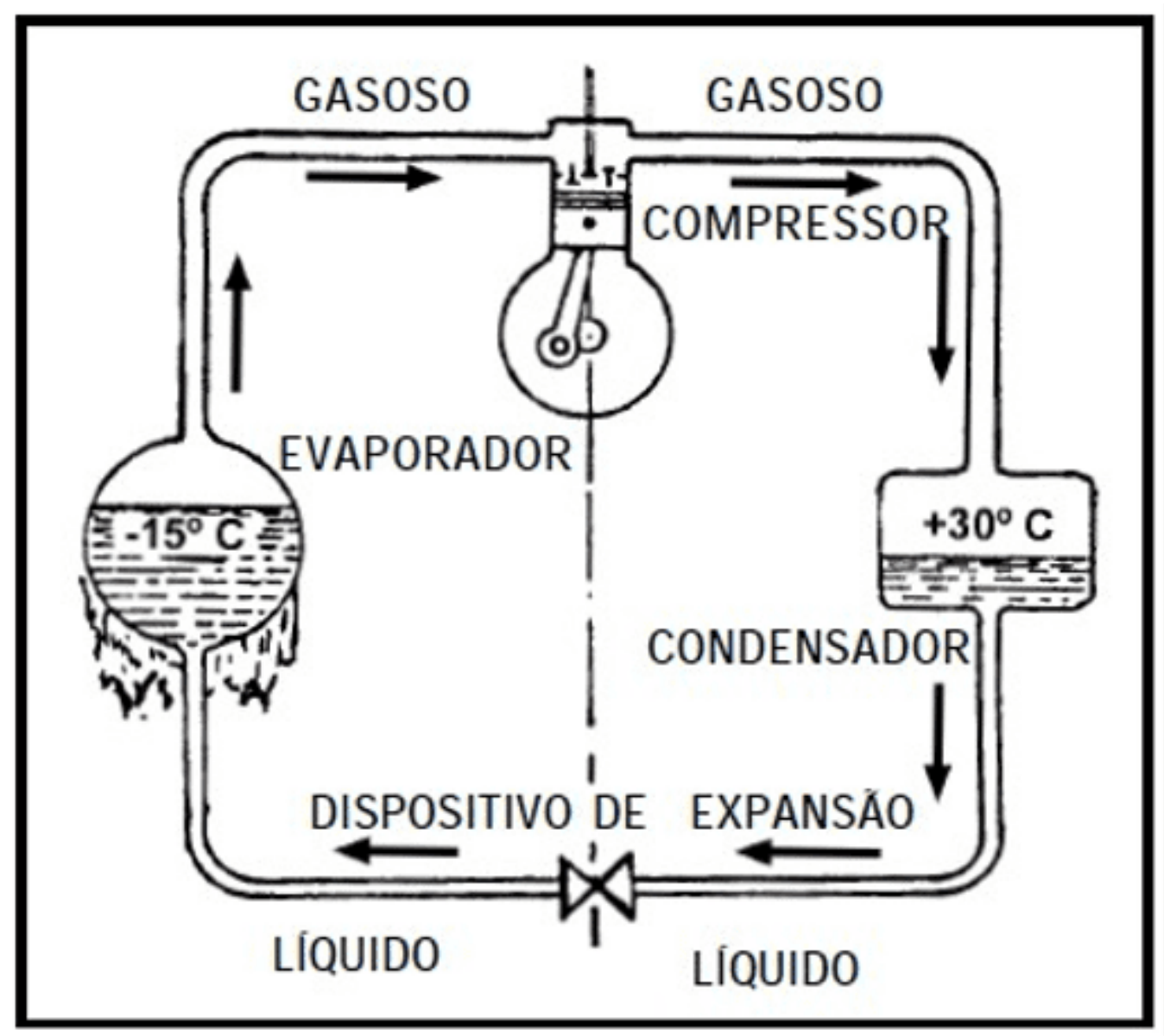

Fonte: Rey, 2019.

Para desenvolvimento do projeto de refrigeração, seguiram as etapas que estão destacadas no Quadro 1.

RC: 96275

Disponível em: https://www.nucleodoconhecimento.com.br/engenhariaquimica/refrigeracao-portatil 
Quadro 1 - Desenvolvimento do protótipo.

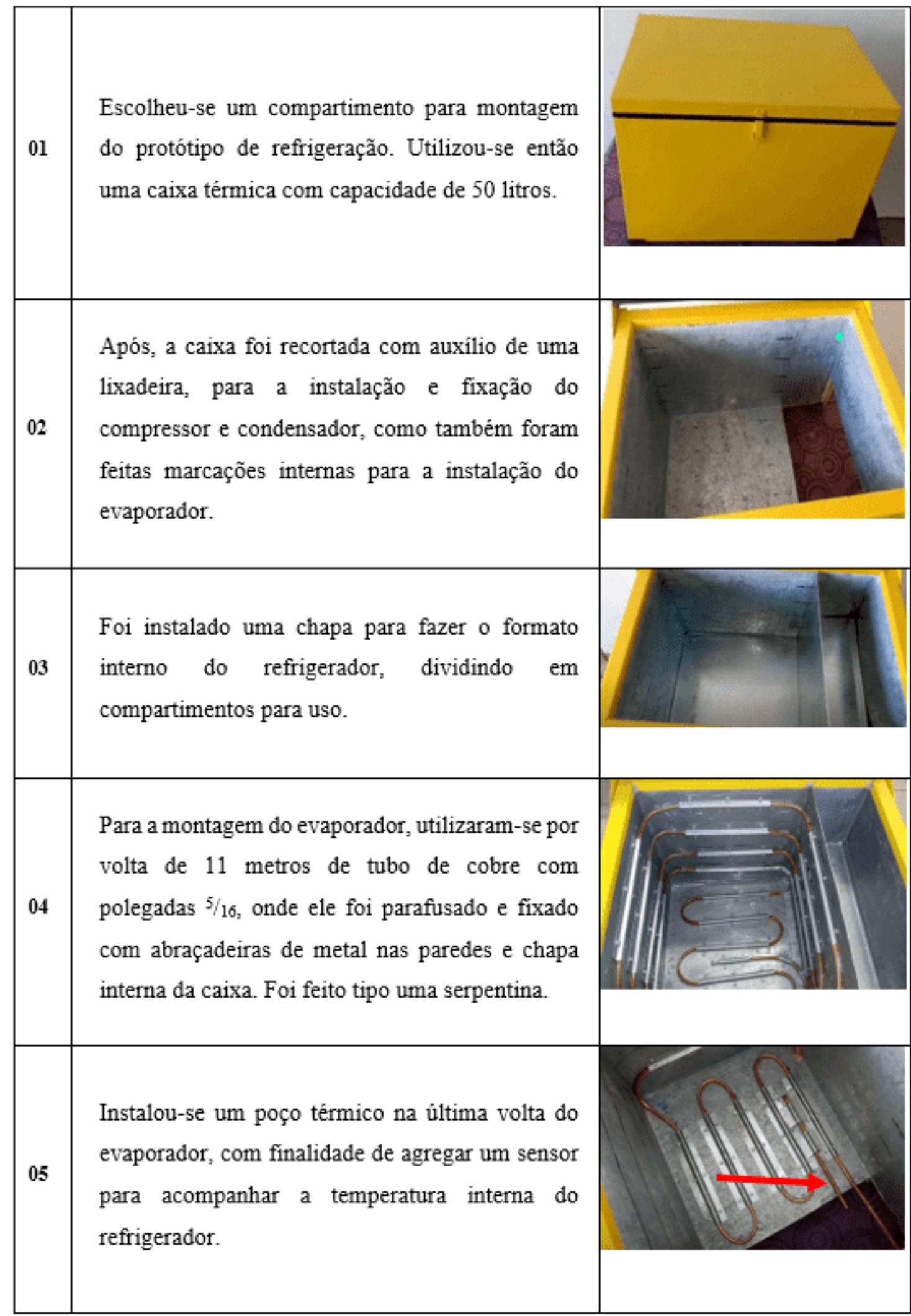

RC: 96275

Disponível em: https://www.nucleodoconhecimento.com.br/engenhariaquimica/refrigeracao-portatil 


\begin{tabular}{|c|c|}
\hline 06 & $\begin{array}{l}\text { Elaborou-se um condensador em formato tipo } \\
\text { mola com } 4 \text { metros de tubo de cobre com } \\
\text { polegadas } 3 / 8 \text {. }\end{array}$ \\
\hline 07 & $\begin{array}{l}\text { A chapa que foi instalada internamente serviu de } \\
\text { proteção para o compressor e condensador. O tudo } \\
\text { de cobre indicado na figura lado, trata-se do } \\
\text { evaporador que será conectado no compressor. }\end{array}$ \\
\hline 08 & $\begin{array}{l}\text { Foi feito uma camada de vedação com isopor e } \\
\text { silicone PU na parte do compressor e } \\
\text { condensador, para que quando ele estiver em } \\
\text { funcionamento, ao gelar, não escorrer água neste } \\
\text { compartimento. }\end{array}$ \\
\hline 09 & $\begin{array}{l}\text { Na sequência, abriu um recorte na parte frontal da } \\
\text { caixa para instalar um controlador de temperatura, } \\
\text { como também alguns furos para garantir } \\
\text { ventilação interna. }\end{array}$ \\
\hline 10 & $\begin{array}{l}\text { Instalou-se um cooler de } 12 \text { Volts para reduzir o } \\
\text { calor gerado pelos componentes deste } \\
\text { compartimento externo, sendo eles o compressor } \\
\text { e o condensador. Para o controle de velocidade de } \\
\text { rotação do cooler, instalou-se um dimmer. }\end{array}$ \\
\hline
\end{tabular}

RC: 96275

Disponível em: https://www.nucleodoconhecimento.com.br/engenhariaquimica/refrigeracao-portatil 


$11 \quad \begin{aligned} & \text { Na saida do condensador, foi instalado um filtro } \\ & \text { secador com objetivo de reter qualquer umidade } \\ & \text { do gás refrigerante. E na saída do filtro secador foi } \\ & \text { conectado a válvula de expansão. }\end{aligned}$

Fonte:

Os autores, 2020.

De acordo com o projeto de mini refrigerador desenvolvido por Seelent (2011), um refrigerador de bebidas com alto rendimento e potência de $960 \mathrm{~W}$, consegue refrigerar de $28^{\circ} \mathrm{C}$ para $0{ }^{\circ} \mathrm{C}, 24$ garrafas de $600 \mathrm{ml}$ em uma hora e vinte minutos. Partindo disso, fez-se os testes no protótipo para verificação da capacidade do compartimento conforme demonstrado na Tabela 2.

TABELA 2: Capacidade de cervejas do Mini Refrigerador Portátil.

\begin{tabular}{|l|l|l|l|}
\hline & COMPARTIMETO FREZER (maior) & $\begin{array}{l}\text { COMPARTIMENTO } \\
\text { GELADEIRA (menor) }\end{array}$ & \\
\hline $\mathbf{1 2}$ & GARRAFAS 1L EM PÉ & +10 GARRAFINHAS $300 \mathrm{~mL}$ & $=22$ \\
\hline $\mathbf{2 0}$ & GARRAFAS $600 \mathrm{MI}$ EM PÉ & +10 GARRAFINHAS $300 \mathrm{~mL}$ & $=30$ \\
\hline $\mathbf{2 2}$ & GARRAFAS $500 \mathrm{MI}$ DEITADA & +10 GARRAFINHAS $300 \mathrm{~mL}$ & $=42$ \\
\hline $\mathbf{5 0}$ & GARRAFAS $300 \mathrm{MI}$ DEITADA & +10 GARRAFINHAS $300 \mathrm{Ml}$ & $=60$ \\
\hline
\end{tabular}

Fonte: Os autores, 2020.

RC: 96275

Disponível em: https://www.nucleodoconhecimento.com.br/engenhariaquimica/refrigeracao-portatil 


\subsection{MÉDIA LOGARÍTMICA DAS DIFERENÇAS DE TEMPERATURAS}

Com intuito de analisar a eficiência do protótipo realizou-se o primeiro teste. Colocou-se o fluido refrigerante em um circuito fechado, que entrou no compressor a temperatura de $-15^{\circ} \mathrm{C}$ e saiu para o sistema de refrigeração a $-12^{\circ} \mathrm{C}$. No interior da caixa térmica, armazenou-se uma cerveja de $500 \mathrm{ml}$ por 30 min que entrou a temperatura ambiente de $29^{\circ} \mathrm{C}$ e que após o tempo de resfriamento, saiu a $19{ }^{\circ} \mathrm{C}$.

Utilizou-se a Equação 1 para o cálculo da MDT, considerando a operação em correntes opostas.

$$
M L D T=\frac{\Delta T_{\text {máxima }}-\Delta T_{\text {minima }}}{\ln \left(\frac{\Delta T_{\text {máxima }}}{\Delta T_{\text {minima }}}\right)}
$$

Onde, é a variação de temperatura máxima, calculada pela subtração entre a temperatura de entrada do fluído quente com a temperatura de saída do fluído frio e é a variação de temperatura mínima, calculada pela subtração da temperatura de saída ou descarga do fluído quente, com a temperatura de entrada do fluído frio.

\subsection{CÁLCULO DA CAPACIDADE TÉRMICA DO REFRIGERADOR}

Do ponto de vista matemático, a capacidade térmica (C) é definida como a razão entre o calor recebido $(Q)$ pelo corpo e a variação de temperatura $(\Delta T)$ sofrida por ele. A expressão que se utiliza a fins de calcular essa relação é a Equação 2.

$$
C=\frac{Q}{\Delta \mathrm{T}}
$$

Onde:

C: capacidade térmica $\left(\mathrm{kJ} / \mathrm{kg}^{\circ} \mathrm{C}\right)$;

RC: 96275

Disponível em: https://www.nucleodoconhecimento.com.br/engenhariaquimica/refrigeracao-portatil 
Q: quantidade de calor $(\mathrm{kJ})$;

$\Delta \mathrm{T}$ : variação de temperatura $\left({ }^{\circ} \mathrm{C}\right.$ ou $\left.\mathrm{K}\right)$.

O Quadro 2 apresenta as especificações da caixa refrigeradora e da garrafa de cerveja.

Quadro 2: Especificações da caixa refrigeradora e garrafa de cerveja.

ESPECIFICAÇÕES

CAIXA REFRIGERADORA

$$
C=\frac{Q}{\Delta \mathrm{T}}
$$

GARRAFA D

E CERVEJA

Capacidade: 50 litros

Massa cerveja: $300 \mathrm{ml}$

Peso: 22 kg

Massa vidro: $240 \mathrm{~g}$

Espessura do isolante térmico

Calor específico do vidro: $0,67 \mathrm{~kJ} / \mathrm{kg}^{\circ} \mathrm{C}$

$0,03 m$

Calor específico da cerveja: $4,27 \quad \mathrm{~kJ} / \mathrm{kg}^{\circ} \mathrm{C}$

Tensão de alimentação: 127 V (SEELENT,2011)

$60 \mathrm{~Hz}$

Dimensão interna da caixa térmica:

Altura: 0,43m Largura: $0,40 \mathrm{~m}$

Comprimento: $0,56 \mathrm{~m}$

Fonte: Os autores, 2020.

A capacidade térmica é proporcional à massa dos corpos. Essa proporcionalidade é definida por uma grandeza denominada calor específico (c), que é determinado pela razão constante entre a capacidade térmica e a massa de uma substância, quanto

RC: 96275

Disponível em: https://www.nucleodoconhecimento.com.br/engenhariaquimica/refrigeracao-portatil 
maior a massa de um corpo, maior a quantidade de calor necessária para variar sua temperatura (TEIXEIRA, 2021).

Logo após, de posse de um termômetro mediu-se a temperatura da caixa e da cerveja em função do tempo e assim calculou a variação da temperatura com a Equação 3.

$$
\Delta T=T_{f}-T_{i}
$$

Onde:

$\Delta \mathrm{T}$ : variação de temperatura $\left({ }^{\circ} \mathrm{C}\right)$

$\mathrm{T}_{\mathrm{f}}$ : temperatura final $\left({ }^{\circ} \mathrm{C}\right)$

$\mathrm{T}_{\mathrm{i}}$ : temperatura inicial $\left({ }^{\circ} \mathrm{C}\right)$

Portanto, calculou-se a Energia Térmica da cerveja com a Equação 4.

$$
Q=\operatorname{mxc} x \Delta t
$$

Onde:

Q: energia térmica $(\mathrm{Kj})$

m: massa $(\mathrm{kg})$

c: calor específico $\left(\mathrm{Kj} / \mathrm{kg}^{\circ} \mathrm{C}\right)$

$\Delta \mathrm{T}$ : variação de temperatura $\left({ }^{\circ} \mathrm{C}\right)$

RC: 96275

Disponível em: https://www.nucleodoconhecimento.com.br/engenhariaquimica/refrigeracao-portatil 


\subsection{CONSUMO DE ENERGIA ELÉTRICA}

Para estimar o consumo de energia elétrica mensal no período 24 horas por dia, utilizou-se Equação 5 e Equação 6.

$$
C=P \times t
$$

$\mathrm{C}$ : consumo de energia elétrica $(\mathrm{kWh})$

P: potência consumida (W)

$\mathrm{t}$ : tempo de funcionamento $(\mathrm{h})$

$C \times h \times 30$

Consumo mensal:

$\mathrm{C}=$ consumo de energia elétrica $(\mathrm{kWh})$

$\mathrm{h}=$ horas de utilização do mini refrigerador

Tomando a Lei de Ohm, junto a fórmula da Figura 3, determinou-se o valor da potência elétrica dissipada pela Equação 7 . 
Figura 3: Representação da Lei de Ohm.

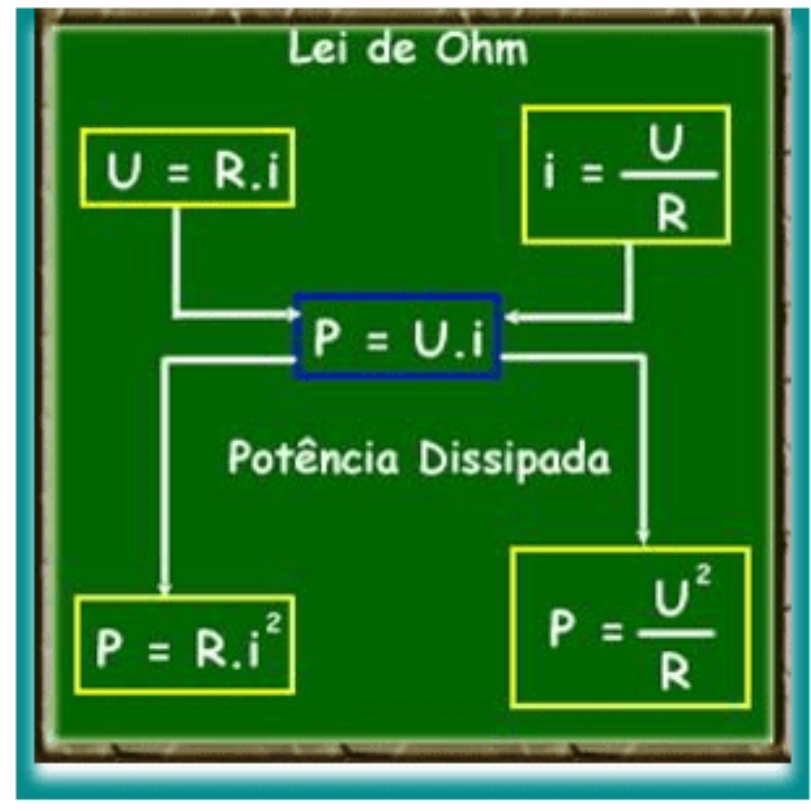

Fonte: (BISQUOLO, 2021).

$$
P=U . i
$$

P: Potência (W)

U: Tensão (V)

I: Corrente elétrica $(A)$

\section{RESULTADO E DISCUSSÃO}

A Tabela 3 demostra os resultados obtidos através dos testes, do valor da MLDT e das temperaturas, tanto de entrada (E) e saída (S) dos fluídos quentes (TQ) e frios (TF) em ${ }^{\circ} \mathrm{C}$. Após a realização dos testes 2 e 3 no tempo estimado de 15 minutos, a quantidade de cerveja continuou armazenada na caixa e observou que no primeiro teste ocorreu a formação de gelo na serpentina de cobre do evaporador. Já no 
segundo e terceiro testes, a formação de gelo continuou aumentando na área refrigerada.

\section{Tabela 3 - Temperaturas e MLDT.}

\begin{tabular}{|l|l|l|l|l|l|}
\hline Teste & $\mathrm{TQ}, \mathrm{E}\left({ }^{\circ} \mathrm{C}\right)$ & $\mathrm{TF}, \mathrm{E}\left({ }^{\circ} \mathrm{C}\right)$ & $\mathrm{TQ}, \mathrm{S}\left({ }^{\circ} \mathrm{C}\right)$ & $\mathrm{TF}, \mathrm{S}\left({ }^{\circ} \mathrm{C}\right)$ & $\mathrm{MLDT}$ \\
\hline $\mathbf{1}$ & 29 & -15 & 19 & -12 & 37,12 \\
\hline $\mathbf{2}$ & 19 & -15 & 15 & -12 & 30,36 \\
\hline $\mathbf{3}$ & 27 & -15 & 19 & -12 & 36,22 \\
\hline
\end{tabular}

Fonte: Os autores, 2020.

Conforme explanações de Silva e Thadeu (2012)

O fluxo de calor transferido entre os fluidos e o trocador de calor é diretamente proporcional à diferença de temperatura média entre os fluidos. No trocador de calor de correntes opostas à diferença de temperatura entre os fluidos não varia tanto, o que gera em uma diferença média maior, como consequência mantida as mesmas condições, logo o trocador de calor trabalhando em correntes opostas é mais eficiente.

Realizou-se um $4^{0}$ teste, para descobrir a capacidade térmica da máquina, onde permite calcular a quantidade de energia trocada (cedida ou recebida) por um corpo. Esta troca de energia é proveniente da variação de temperatura do protótipo. $\mathrm{O}$ Quadro 3 mostra a variação da temperatura da caixa em função do tempo.

Quadro 3: Variação de temperatura da caixa.

\begin{tabular}{|l|l|}
\hline $\begin{array}{l}\mathrm{T} \\
(\min )\end{array}$ & $\mathrm{T}^{\circ} \mathrm{C}$ \\
\hline $\mathbf{0}$ & 22,5 \\
\hline $\mathbf{1 5}$ & 18 \\
\hline $\mathbf{3 0}$ & 10,9 \\
\hline $\mathbf{4 5}$ & 6,8 \\
\hline
\end{tabular}

RC: 96275

Disponível em: https://www.nucleodoconhecimento.com.br/engenhariaquimica/refrigeracao-portatil 


\begin{tabular}{|l|l|}
\hline $\mathbf{6 0}$ & 4,1 \\
\hline $\mathbf{7 5}$ & 3,1 \\
\hline $\mathbf{9 0}$ & 2,4 \\
\hline $\mathbf{1 0 5}$ & 1,6 \\
\hline $\mathbf{1 2 0}$ & 1,2 \\
\hline $\mathbf{1 3 5}$ & 0,5 \\
\hline $\mathbf{1 5 0}$ & $-1,1$ \\
\hline
\end{tabular}

Fonte: Os autores, 2020.

Analisando os resultados do Quadro 3, foi possível elaborar o gráfico da Figura 4 para identificar a curva das variações de temperatura. Observa-se que quanto maior o tempo de refrigeração menor a temperatura, confirmando a eficiência do equipamento.

Figura 4: Gráfico das variações de temperatura.

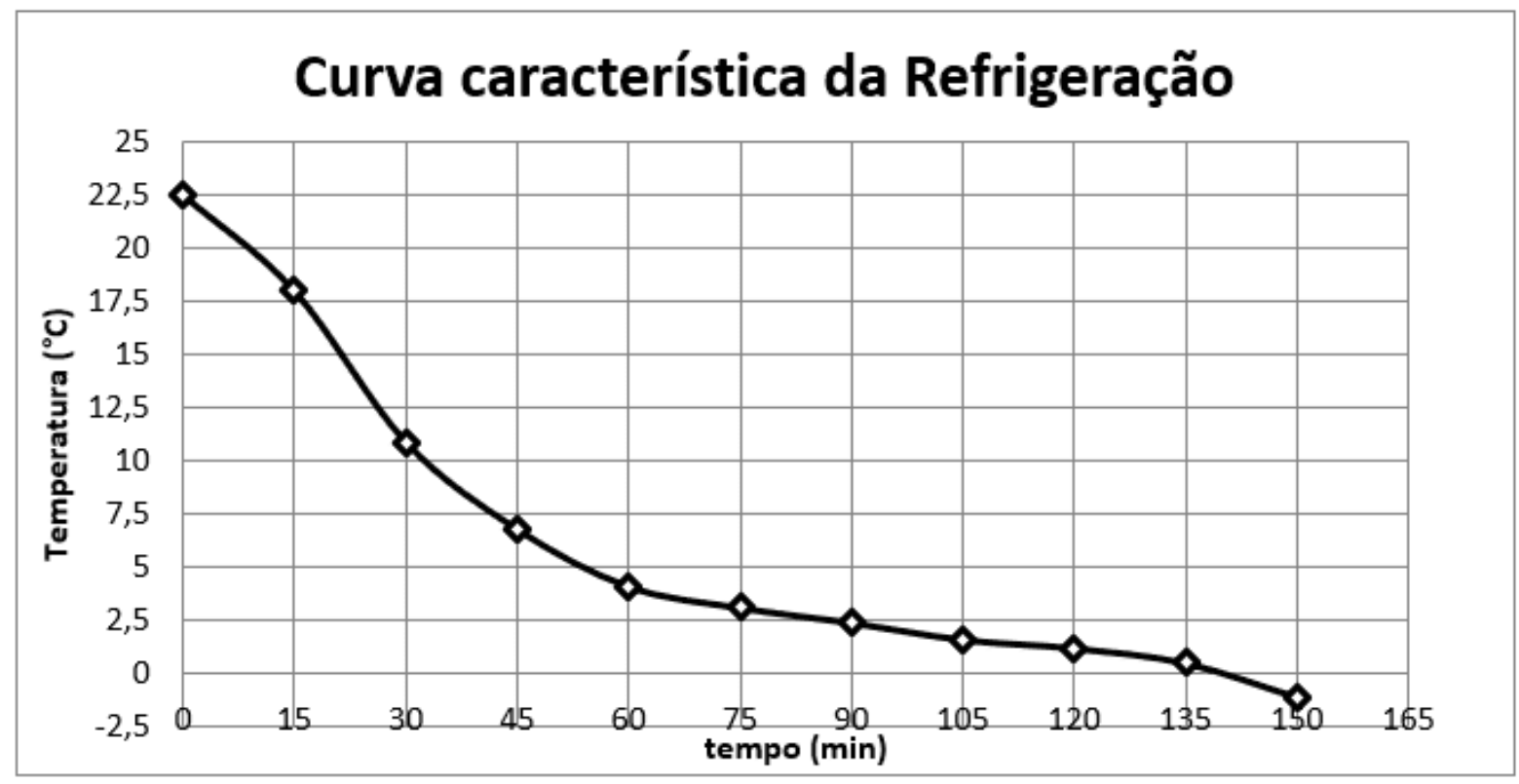

Fonte: Os autores, 2020.

RC: 96275

Disponível em: https://www.nucleodoconhecimento.com.br/engenhariaquimica/refrigeracao-portatil 
A Figura 5 apresenta a temperatura inicial e final da cerveja, sendo $27,5^{\circ} \mathrm{C}$ e $5,7^{\circ} \mathrm{C}$, respectivamente.

Figura 5: Temperatura da cerveja.

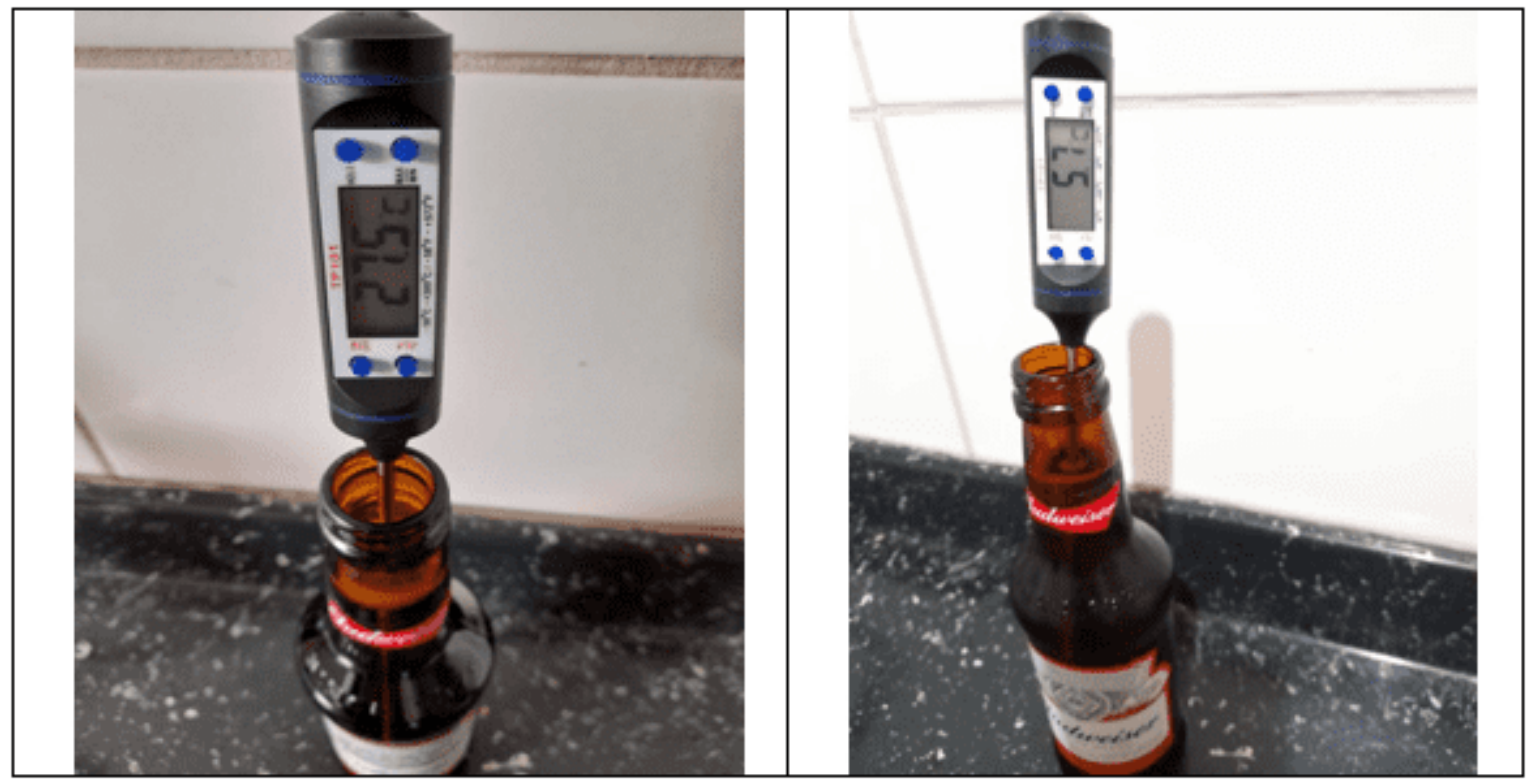

Fonte: Os autores, 2020.

Calculou-se a variação da temperatura da cerveja e da caixa, $\Delta$ Tcerveja $=5,7-27,5=-21,8{ }^{\circ} \mathrm{C}$

$\Delta$ Tcaixa $=-1,1-22,5=23,6{ }^{\circ} \mathrm{C}$ 'respectivamente.

Após, determinou-se a energia térmica total da cerveja e da caixa refrigeradora, sendo igual Qtotal $=-34,22 \mathrm{~kJ}$.

Assim, efetuou-se o cálculo da capacidade térmica da caixa e da cerveja, obtendo um valor de $\mathrm{C}=-1,45 \mathrm{~kJ} / \mathrm{kg} /{ }^{\circ} \mathrm{C}$.

O resultado $-1,45 \mathrm{~kJ} / \mathrm{kg}^{\circ} \mathrm{C}$ da capacidade térmica indica que o material perdeu calor e diminuiu a energia do sistema, ou seja, a energia térmica está saindo do corpo.

RC: 96275

Disponível em: https://www.nucleodoconhecimento.com.br/engenhariaquimica/refrigeracao-portatil 
Isso ocorre quando um corpo recebe ou perde calor e a temperatura aumenta ou diminui, ocorrendo assim a mudança de estado e agregação das moléculas, do estado sólido para líquido, líquido para vapor, ou vice-versa (SCHULZ, 2009). Segundo Bekon (2019) como a capacidade máxima do refrigerador é de 60 garrafas de $300 \mathrm{ml}$, a carga máxima de calor no interior da caixa será 2053,2 kJ. O protótipo atingiu o valor esperado de $-1,1^{\circ} \mathrm{C}$ abaixo de $0{ }^{\circ} \mathrm{C}$ visto que não necessariamente poderemos ter a carga máxima.

Com o auxílio de um Alicate Amperímetro Digital mediu-se a tensão média e a corrente elétrica, resultando em $127 \mathrm{~V}$ e 1,07 A, respectivamente e encontrou o valor da potência dissipada em .

Como a taxa por kWh é aproximadamente $R \$ 0,33$, estimou-se o gasto de energia elétrica do mini refrigerador por mês em

Quadro 4: Informações de eficiência energética.

\begin{tabular}{|c||c|c|c|}
\hline Aparelhos Elétricos & $\begin{array}{c}\text { Dias } \\
\text { Estimados } \\
\text { Uso/Mês }\end{array}$ & $\begin{array}{c}\text { Média } \\
\text { Utilização/Dia }\end{array}$ & $\begin{array}{c}\text { Consumo } \\
\text { Médio Mensal } \\
\text { (kWh) }\end{array}$ \\
\hline $\begin{array}{c}\text { Feezer } \\
\text { vertical/horizontal }\end{array}$ & 30 & $24 \mathrm{~h}$ & 47,55 \\
\hline $\begin{array}{c}\text { Freezer vertical frost } \\
\text { free }\end{array}$ & 30 & $24 \mathrm{~h}$ & 54,00 \\
\hline Frigobar & 30 & $24 \mathrm{~h}$ & 18,90 \\
\hline Geladeira 1 porta & 30 & $24 \mathrm{~h}$ & 25,20 \\
\hline $\begin{array}{c}\text { Geladeira 1 porta } \\
\text { frost free }\end{array}$ & 30 & $24 \mathrm{~h}$ & 39,60 \\
\hline Geladeira 2 portas & 30 & $24 \mathrm{~h}$ & 48,24 \\
\hline $\begin{array}{c}\text { Geladeira 2 portas } \\
\text { frost free }\end{array}$ & 30 & $24 \mathrm{~h}$ & 56,88 \\
\hline
\end{tabular}

Fonte: Procelinfo, 2006.

RC: 96275

Disponível em: https://www.nucleodoconhecimento.com.br/engenhariaquimica/refrigeracao-portatil 
Figura 6: Valores do kWh das companhias elétricas.

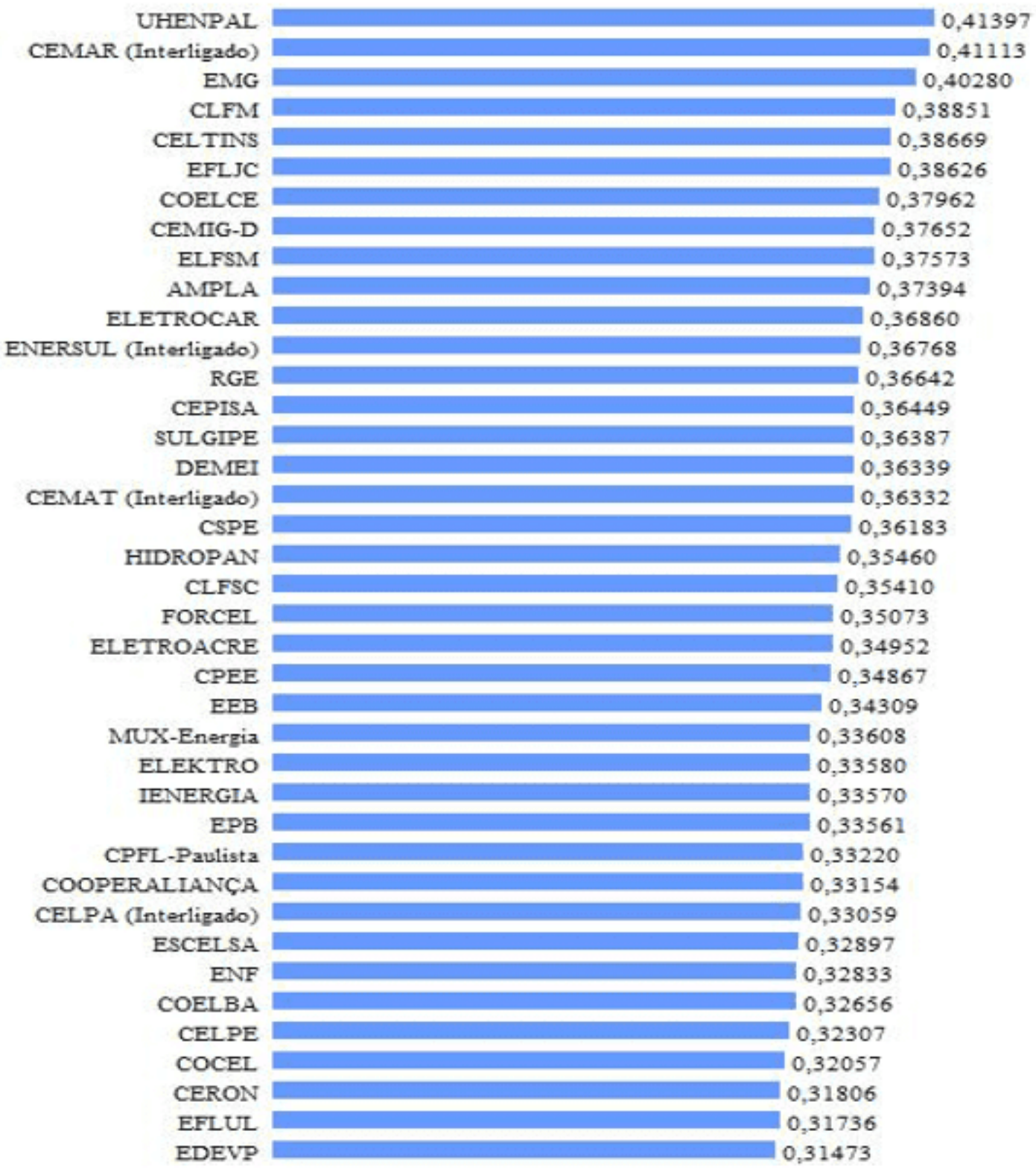

Fonte: Coelho, 2012.

Portanto, o consumo mensal do mini refrigerador foi de $R \$ 32,29$ durante 30 dias, e conforme o Quadro 4, observa-se que o valor do protótipo é relativamente próximo ao freezer horizontal/vertical, que de acordo com a Figura 6, a taxa administrativa das companhias elétricas é variável. Segundo Kronbauer (2013) no qual possui um

RC: 96275

Disponível em: https://www.nucleodoconhecimento.com.br/engenhariaquimica/refrigeracao-portatil 
refrigerador de capacidade 3 litros compostos de pastilhas termoelétricas que operam utilizando o efeito Peltier, gastou-se $5,88 \mathrm{kWh}$ por mês utilizando a caixa $4 \mathrm{~h}$ por dia. Portanto, verificou-se que o projeto gastou menos energia e possui uma capacidade maior.

\section{CONCLUSÃO}

O desenvolvimento deste trabalho abrange conhecimentos práticos e teóricos do processo de refrigeração, que possibilita essa flexibilidade de transporte devido ao seu tamanho, podendo ser reproduzido facilmente e com baixo custo de fabricação.

Elaborou-se um modelo de refrigeração portátil por compressão a vapor com refrigerante ecológico (R-409) para o resfriamento de bebidas e alimentos, composto basicamente por um evaporador onde o fluido adentra a baixa pressão, compressor onde o gás é comprimido e bombeado e condensador evaporativo atmosférico.

Através dos cálculos referente ao método (MLDT) e testes de funcionamento, o protótipo apresentou uma queda de temperatura de $27,1^{\circ} \mathrm{O}$ em 150 minutos sendo que o fluído em temperatura ambiente de $26 \stackrel{\circ}{\circ}$, atingiu ao término do processo a temperatura de $-1,1{ }^{\circ} \mathrm{C}$, resultado satisfatório comparado com a literatura.

À vista disso, o protótipo suportou a capacidade de até 60 garrafas de $300 \mathrm{ml}$, promovendo uma economia energética considerável, já que depende de uma fonte elétrica para realizar trabalho.

Diante disso o projeto comprovou sua eficiência que validou dados adeptos com a literatura, gerando resultados satisfatórios para essa versão do protótipo.

\section{REFERÊNCIAS}

BEKON, Sidnei: Novo mini refrigerador portátil I: Projeto e Execução da Estrutura e Condensador, 2019. Disponível em: <https://www.researchgate.net/publication/336747810_Novo_Minirefrigerador_Portati 
I_I_Projeto_e_Execucao_da_Estrutura_e_Condensador> Acesso em: 23 de fevereiro 2021.

BISQUOLO, Paulo Augusto, Potência elétrica - Cálculo do consumo de energia elétrica, 2021. Disponível em: $<$ https://educacao.uol.com.br/disciplinas/fisica/potencia-eletrica-calculo-do-consumode-energia-eletrica.htm>. Acesso em: 27 de fevereiro 2021.

BORGNAKKE, Claus, SONNTAG Richard. Fundamentos da Termodinâmica, 2002. Disponível em: <http://repositorio.unicamp.br/jspui/handle/REPOSIP/261696>. Acesso em: 21 de Abril de 2021.

CARMEIS, Dean Willian Moraes. Os efeitos da diversidade de tensões de distribuição no setor elétrico brasileiro: Estudo do Caso do Refrigerador Doméstico, 2002. Disponível em: <http://repositorio.unicamp.br/jspui/handle/REPOSIP/261696>. Acesso em: 21 de abril 2021.

COELHO, Barbara. Tarifação da Energia Elétrica, 2012. Disponível em: <http://www2.dbd.puc-rio.br/pergamum/tesesabertas/1012705_2012_cap_6.pdf>. Acesso em: 31 de julho 2021.

EVANGELISTA, Carla Reis. Vaporização, 2010. Disponível em: $<$ https://www.infoescola.com/termodinamica/vaporizacao/amp/>. Acesso em: 22 de fevereiro 2021.

FERRAZ, Fábio. Apostila de refrigeração. Centro Federal de Educação Tecnológica, 2008. Disponível em: < https://fabioferrazdr.files.wordpress.com/2008/09/ref13.pdf>. Acesso em: 06 de março 2021. 
JÚNIOR, Luiz Carlos Martinelli. Refrigeração, 2003. 134p. Disponível em: < http://www.portaldoeletrodomestico.com.br/cursos/refrigeracao_ar/apostila_refrigerac ao.pdf>. Acesso em: 14 de abril 2021.

KRONBAUER, Ana Claudia do: Projeto e construção de um mini refrigerador com pastilhas termoelétricas, 2013. Disponível em: <http://riut.utfpr.edu.br/jspui/bitstream/1/13610/2/MD_COMIN_2012_2_03.pdf>. Acesso em: 14 de abril 2021.

MARQUES, João Carlos Borges. Análise de desempenho de um refrigerador de pequeno porte com drop in de refrigerantes hidrocarbonetos, 2010. Disponível em:

https://repositorio.ufrn.br/jspui/bitstream/123456789/15655/1/JoaoCBM_DISSERT.pd f>. Acesso em: 29 de julho 2021.

MARTÍNEZ, Luiz Carlos Castilho. Otimização dos circuitos de refrigerante nos trocadores de calor de sistemas de refrigeração por compressão de vapor, 2009. Disponível em: < https://www.maxwell.vrac.puc-rio.br/31763/31763_4.PDF>. Acesso em: 23 de janeiro de 2021.

MCKINLEY, Thomas; ALLEYNE, Andrew. Um modelo avançado de trocador de calor não linear comutado para ciclos de compressão de vapor usando o método de limite móvel, 2008. Disponível em: < https://experts.illinois.edu/en/publications/an-advanced-nonlinear-switched-heatexchanger-model-for-vapor-com>. Acesso em: 13 de maio 2021.

MORAIS, André Neves. Simulação numérica de um ciclo de refrigeração por absorção, 2012. Disponível em:

https://bdm.unb.br/bitstream/10483/3374/1/2012_AndreNevesdeMoraes.pdf>. Acesso em: 26 de julho 2021.

NUNES, Tallita Karolline. Modelagem, simulação e otimização de sistemas de refrigeração por compressão de vapor, 2015. Disponível em: 


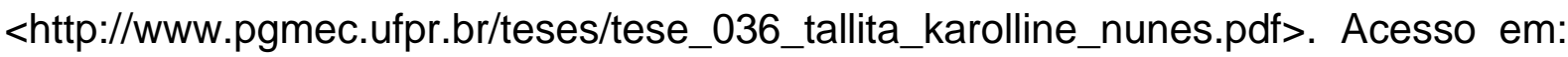
28 de julho 2021.

OLIVEIRA, Mário Henrique da Fonseca; REBELLATO, Daisy Aparecida do Nascimento; YAMASHITA, Bruno Dantas. Análise dos refrigeradores e freezers utilizados no Brasil e de novas tecnologias que possam aumentar sua eficiência energética.

Disponível

em:

$<$ https://revista.feb.unesp.br/index.php/gepros/article/viewFile/1484/735\#: :text=O\%2 Ofen\%C3\%B4meno\%20da\%20refrigera\%C3\%A7\%C3\%A30\%20\%C3\%A9,conforme \%20exposto\%20pela\%20Figura\%201>. Acesso em: 27 de julho 2021.

PROCELINFO, Blog. Centro brasileiro de informação de eficiência energética, 2006.

Disponível em:

http://www.procelinfo.com.br/main.asp?View=\%7BE6BC2A5F-E787-48AF-B485439862B17000\%7D>. Acesso em: 25 de julho 2021.

REY, Anderson. Os tipos de refrigeração - Curso de refrigeração, 2019. Disponível em: <https://refrimaq.org/os-tipos-de-refrigeracao/>. Acesso em: 22 de fevereiro de 2021.

SALVADOR, Francisco. Modelagem e simulação de sistemas de refrigeração de pequeno porte com dispositivo de expansão constituído por tubo capilar, 1999. Disponível em: <https://www.teses.usp.br/teses/disponiveis/3/3139/tde-05102010112239/publico/Dissertacao_Francisco_Salvador.pdf>. Acesso em: 29 de julho 2021.

SCHULZ, Daniel. Capacidade térmica, 2009. Disponível em: $<$ https://www.if.ufrgs.br/ dschulz/web/capacidade_termica.htm>. Acesso em: 20 de fevereiro de 2021.

SEELENT, Jonas Josiel. Refrigeradores de bebidas de alto rendimento, 2011. Disponível em: $<$ https://repositorio.utfpr.edu.br/jspui/bitstream/1/13706/2/MD_COMIN_2011_2_08.pd f>. Acesso em: 25 de julho 2021.

RC: 96275

Disponível em: https://www.nucleodoconhecimento.com.br/engenhariaquimica/refrigeracao-portatil 
SILVA, Thadeu Alfredo Farias da. Atenuação térmica nos grupos geradores de energia utilizando trocadores de calor de água gelada controlada, 2012. Disponível em: http://repositorio.unicamp.br/bitstream/REPOSIP/266690/1/Silva_ThadeuAlfredoFari as_M.pdf $>$. Acesso em: 21 de abril 2021.

TEIXEIRA, Mariane Mendes. Equação fundamental da calorimetria, 2021. Disponível em: $\quad<$ https://m.mundoeducacao.uol.com.br/amp/fisica/equacao-fundamentalcalorimetria.htm/>. Acesso em: 05 de maio 2021.

Enviado: Junho, 2021.

Aprovado: Setembro, 2021. 